\title{
Vertically unstable sacral fractures with neurological insult: outcomes of surgical decompression and reconstruction plate internal fixation
}

\author{
Mostafa A. Ayoub
}

Received: 22 June 2007 / Accepted: 3 September 2007 / Published online: 27 October 2007

(C) Springer-Verlag 2007

\begin{abstract}
During a 4-year period, 32 patients with type C unstable sacral fractures were treated in our university hospital. All patients had neurological deficits as a result of their sacral fracture. The average age was 31.2 (range 2254) years and the average Hannover Polytrauma Score (PTS) was 24 (range 19-40) points. Twelve patients had zone I fracture, ten had zone II fracture and ten patients had comminuted fractures involving both zones. All patients underwent surgical decompression and reconstruction plate internal fixation. The average follow up period was 24.4 (range 19-47) months. Twenty-one patients (65.6\%) had complete neurological recovery, eight patients $(25 \%)$ had partial recovery and three patients $(9.4 \%)$ had no recovery. The relationship between radiological and functional scores was evident but insignificant $(P=0.434)$. Significantly, the neurological recovery was less favourable in older age groups, pedestrian trauma, vertical shear injuries, comminuted fractures, fifth lumbar root involvement, very low motor power grades and in patients presenting late. Concerning complications, four patients $(12.5 \%)$ had early infection and five patients (15.6\%) had late urological problems and heterotopic ossification. Consequently, we conclude that patients undergoing very early surgical decompression and only reconstruction plate internal fixation can achieve safe early ambulation and better neurological, functional and radiological results.
\end{abstract}

\footnotetext{
M. A. Ayoub $(\square)$

Department of Orthopaedic Surgery and Traumatology,

Tanta University Hospital,

Al-Geish Street,

Tanta, Egypt

e-mail: maayoub@yahoo.com
}

Résumé Sur une période de 4 ans, 32 patients présentant une fracture instable du sacrum de type $\mathrm{C}$ ont été traités dans notre hôpital universitaire. Ces patients présentaient un déficit neurologique secondaire à la fracture. La moyenne d'âge était de 31,2 ans (de 22 à 54) et le score d'Hannover Polytrauma (PTS) de 24 (de 19 à 40). 12 patients présentaient une fracture en zone I, 10 en zone II et 10 patients avaient une fracture comminutive à cheval sur les deux zones. Tous les patients ont bénéficié d'une décompression chirurgicale et d'une reconstruction avec fixation interne par plaque. Le suivi moyen a été de 24,4 mois (19 à 47). 21 patients $(65,6 \%)$ ont complètement récupéré sur le plan neurologique, $8(25 \%)$ ont bénéficié d'une récupération partielle et $3(9,4 \%)$ n'ont pas récupéré. La relation entre le score fonctionnel et l'état radiographique est évident, n'est pas significatif $(\mathrm{P}=0.434)$. De façon significative, la récupération neurologique est moins favorable chez des sujets âgés dont les traumatismes par cisaillement, les traumatismes " pédestres ", les fractures comminutives, avec lésion de la $5^{\text {ème }}$ racine lombaire. Du point de vue complication, 4 patients $(12,5 \%)$ présentaient une infection précoce et 5 patients $(15,6 \%)$ des problèmes urologiques tardifs ainsi que des ossifications hétérotypiques. En conclusion, nous pouvons indiquer que les patients ayant bénéficié d'une décompression chirurgicale précoce avec reconstruction par plaque ont bénéficié d'une reprise de la marche d'une façon sûre avec de meilleurs résultats neurologiques, fonctionnels et radiologiques.

\section{Introduction}

The sacrum and its surrounding ligaments form the integral foundation for the structural integrity of the lumbar spine and the posterior pelvic ring. In addition, it provides the 
protective conduit for major neurovascular structures, supplying the pelvis and lower extremities. Therefore, injury may lead to mechanical, vascular and neurological instability $[1,18]$.

In addition to the high incidence of early associated neurological injuries, inadequately treated unstable sacral fractures may lead to painful malunion and late progressive loss of neurological function, which can be avoided by early surgical intervention [2].

Various options for management have been proposed for unstable sacral fractures $[5,13,21]$ but few studies have concentrated on decompression of the sacral roots, recovery and factors affecting this recovery. Consequently, this study evaluates and analyses the outcomes of surgically managed vertically unstable sacral fractures with neurological injuries through sacral root decompression and reconstruction plate internal fixation.

\section{Patients and methods}

Between 2001 and 2005 in Tanta University Hospital, Egypt, 32 cases of vertically unstable sacral fractures with neurological injury were internally fixed by reconstruction plate after decompression. Table 1 shows the demographic data of the patients. The average age was 31.2 (range 2254) years, 21 cases followed road traffic accidents and 11 cases had a history of a fall from height. All cases had anterior pubic arch fractures and type $\mathrm{C}$ pelvic injuries according to Tile's classification [21]. Twenty-two cases had a polytrauma with an average of 24 (range 19-40) points of the Hannover Polytrauma Score (PTS) [14]. According to Denis et al.'s classification [3], 12 cases were zone II fractures, ten cases were zone I fractures and ten cases had comminuted fractures, which were zone II fractures with lateral extensions to zone I. To decrease other factors which could influence the outcomes, cases with associated neurological insults due to head and spinal injuries or acetabular fracture dislocations were excluded, as well as cases with associated displaced acetabular fractures which were in need for operative intervention. After first aid and general cardiorespiratory stabilisation, full clinical and neurological examinations were performed, including motor power grading, reflexes and sensory testing up to the perianal area. Radiological assessment depended on plain X-ray views (anteroposterior, inlet, outlet and lateral views) and on computed tomography (CT) scans. In pubic fractures, displacements were less than $20 \mathrm{~mm}$, so no internal fixation was planned for them according to Matta's suggestion [12].

After good preoperative planning, surgery was performed according to Tscherne et al. [23] in the first (1$72 \mathrm{~h}$ after trauma), secondary (4-8 days) or tertiary phase
Table 1 Demographic and preoperative data of the patients

\begin{tabular}{|c|c|c|}
\hline \multicolumn{2}{|l|}{ Data } & \multirow{2}{*}{$\frac{\text { Number }}{20}$} \\
\hline Gender & Males & \\
\hline & Females & 12 \\
\hline \multirow[t]{4}{*}{ Age groups } & $21-30$ years & 13 \\
\hline & $31-40$ years & 11 \\
\hline & $41-50$ years & 5 \\
\hline & $51-60$ years & 3 \\
\hline \multirow[t]{4}{*}{ Injury history } & Pedestrians & 9 \\
\hline & Motor cycle & 7 \\
\hline & Car occupants & 5 \\
\hline & Fall from height & 11 \\
\hline \multirow[t]{2}{*}{ Injured side } & Right & 19 \\
\hline & Left & 13 \\
\hline \multirow[t]{3}{*}{ Injury mechanism } & APC & 15 \\
\hline & VS & 10 \\
\hline & $\mathrm{CM}$ & 7 \\
\hline \multirow[t]{12}{*}{ Associated injuries } & Head injury & 4 \\
\hline & Chest injuries & 7 \\
\hline & Abdominal injuries & 6 \\
\hline & Urological injuries & 9 \\
\hline & $\begin{array}{l}\text { Spine fractures without } \\
\text { neurological injury }\end{array}$ & 5 \\
\hline & Upper limb injuries & 6 \\
\hline & Lower limb injuries & 8 \\
\hline & $\begin{array}{l}\text { Non-displaced acetabular } \\
\text { fractures }\end{array}$ & 2 \\
\hline & Contralateral crescent fracture & 1 \\
\hline & $\begin{array}{l}\text { Ipsilateral L-5 transverse } \\
\text { process fracture }\end{array}$ & 14 \\
\hline & Ipsilateral L5-S1 facet joint injury & 4 \\
\hline & Posterior Morel-Lavalle lesion & 5 \\
\hline \multirow[t]{4}{*}{ Injured roots } & $\mathrm{L} 5+\mathrm{S} 1$ & 10 \\
\hline & $\mathrm{S} 1+\mathrm{S} 2$ & 11 \\
\hline & $\mathrm{S} 1$ & 8 \\
\hline & $\mathrm{S} 1+\mathrm{S} 2+\mathrm{S} 3$ & 3 \\
\hline \multirow[t]{4}{*}{ Radicular pain } & None & 15 \\
\hline & Mild (intermittent) & 9 \\
\hline & $\begin{array}{l}\text { Moderate (initiated by } \\
\text { motion in bed) }\end{array}$ & 6 \\
\hline & Severe (continuous) & 2 \\
\hline \multirow[t]{3}{*}{ Sensory defects } & None & 7 \\
\hline & Mild with subjective tolerance & 15 \\
\hline & $\begin{array}{l}\text { Moderate with subjective } \\
\text { intolerance }\end{array}$ & 10 \\
\hline \multirow{3}{*}{$\begin{array}{l}\text { Motor power } \\
\text { defects }\end{array}$} & Grades $0-1 / 5$ & 7 \\
\hline & Grades $2 / 5$ & 13 \\
\hline & Grades $3 / 5$ & 12 \\
\hline \multirow{2}{*}{$\begin{array}{l}\text { Pubic fractures } \\
\text { separation }\end{array}$} & $5-10 \mathrm{~mm}$ & 18 \\
\hline & $11-20 \mathrm{~mm}$ & 14 \\
\hline \multirow{2}{*}{$\begin{array}{l}\text { Posterior vertical } \\
\text { displacement }\end{array}$} & $5-10 \mathrm{~mm}$ & 15 \\
\hline & $11-20 \mathrm{~mm}$ & 17 \\
\hline \multirow[t]{3}{*}{ Timing of surgery } & Primary & 13 \\
\hline & Secondary & 10 \\
\hline & Tertiary & 9 \\
\hline
\end{tabular}

$\mathrm{APC}=$ anteroposterior compression; $\mathrm{VS}=$ vertical shear; $\mathrm{CM}=$ combined mechanism; L=lumbar; $\mathrm{S}=$ sacral 
Fig. 1 A 27-year-old male had a crushing car injury. He sustained straddle fracture of the pubic arch and right-sided type $\mathrm{C}$ sacral fracture with severe zones I and II comminution and proximal migration with entrapment of the L5 and S1 roots (a, b). Surgery was accomplished in the secondary phase and neurological recovery continued up to 19 months with good functional score and excellent radiological score (c)

(more than 8 days), depending on the general condition of each patient. The approaches were two dorsal vertical incisions, one was just medial to the posterior superior iliac spine (PSIS) on the fractured side and the other was lateral to the PSIS on the intact side. After exposure, a laminar spreader was applied gently to allow decompression of the roots, which were contused, compressed by retropulsed or propulsed loose fragments, and kinked between the displaced fracture ends. No cases had transection of the roots. After satisfactory decompression, reduction, with the aid of a Schanz screw inserted into the iliac crest with a T-handle and a large reduction clamp, was achieved under $\mathrm{C}$-arm control. Small rectangles of the iliac crest on both sides, between the posterior superior and inferior iliac spines, were removed to adapt the width and height of the 4.5-mm reconstruction plate. After template and plate contouring, the plate was slid across a transverse subperiosteal tunnel on the dorsal surface of the sacrum and then fixed. The applied plate took the shape of inverted letter ' $U$ ' with divergent limbs. Wounds were closed over suction drains and the deep-seated plate. On the third postoperative day, passive and active rehabilitation programs started, which included gradual training for under-arm crutches or cane ambulation with full weight-bearing on the healthy side and non-weight-bearing on the affected side. The ambulation program was delayed for comminuted fracture cases and in associated upper or lower limb injuries. The ten cases with partial foot drop were supported with ankle foot orthosis (AFO) during rehabilitation and recovery. Postoperatively, plain X-rays were done immediately and at 3 -week intervals until complete radiological healing was achieved. Thereafter, they were repeated every three months during the follow up period, which averaged 24.4 (range 19-47) months.

\section{Results assessment}

The radiological results relied on the maximal anterior or posterior displacement reached at the end of the follow up periods of each patient. By way of constructing horizontal reference lines through bony landmarks according to Henderson, the vertical displacement of the fracture was measured [7]. The results were classified according to Lindahl et al. [9] into the following groups: excellent (0$5 \mathrm{~mm}$ displacement), good $(6-10 \mathrm{~mm})$, fair $(11-15 \mathrm{~mm})$ and poor (more than $15 \mathrm{~mm}$ displacement). The functional results were classified according to Lindahl et al.'s

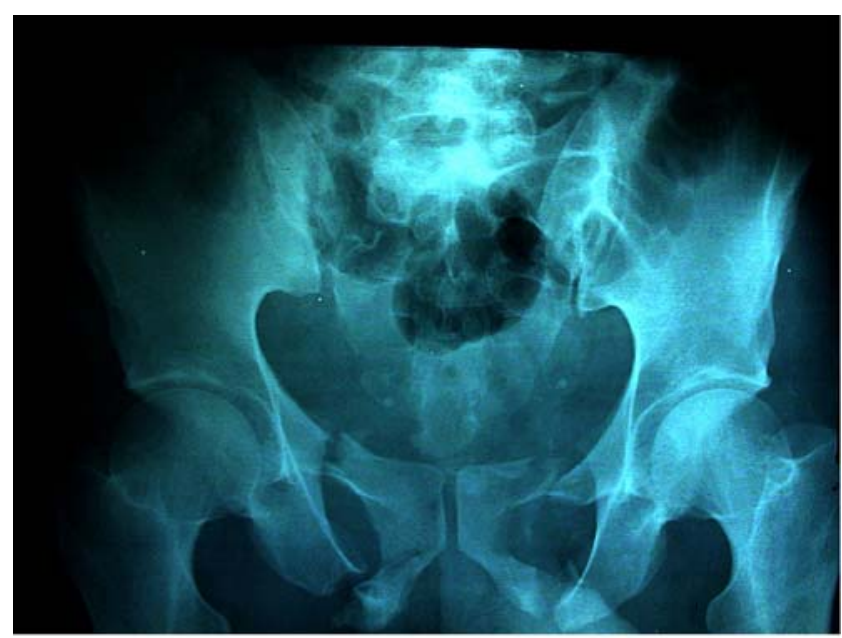

a

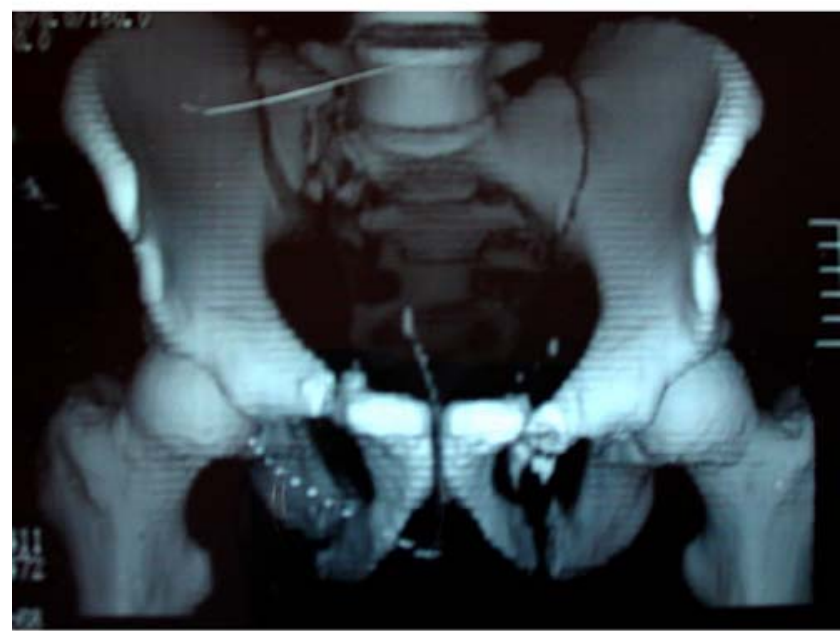

b

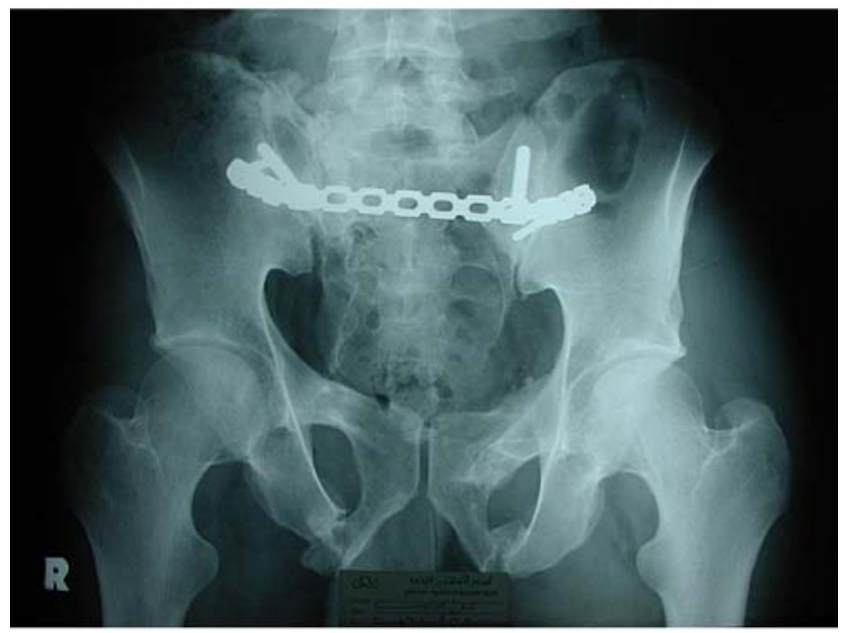

C

modification of the Majeed score into the following groups: excellent (78-80 points), good (70-77 points), fair (60-69 points) and poor ( $<60$ points) $[9,11]$. The one-way analysis of variance (ANOVA) test and, if needed, its rank were 
used for the statistical analysis of the results, with significant findings when the $P$ value was less than 0.05 .

\section{Results}

In this series, radiologically, 16 cases had excellent results (Fig. 1), 11 cases had good results (Fig. 2), four cases had fair results and one case had a poor result. All unsatisfactory radiological results were due to residual posterior displacement noticed postoperatively in two cases and anterior redisplacement in three cases during the follow up period.

Functionally, nine cases achieved excellent results with complete neurological recovery, 13 cases achieved good

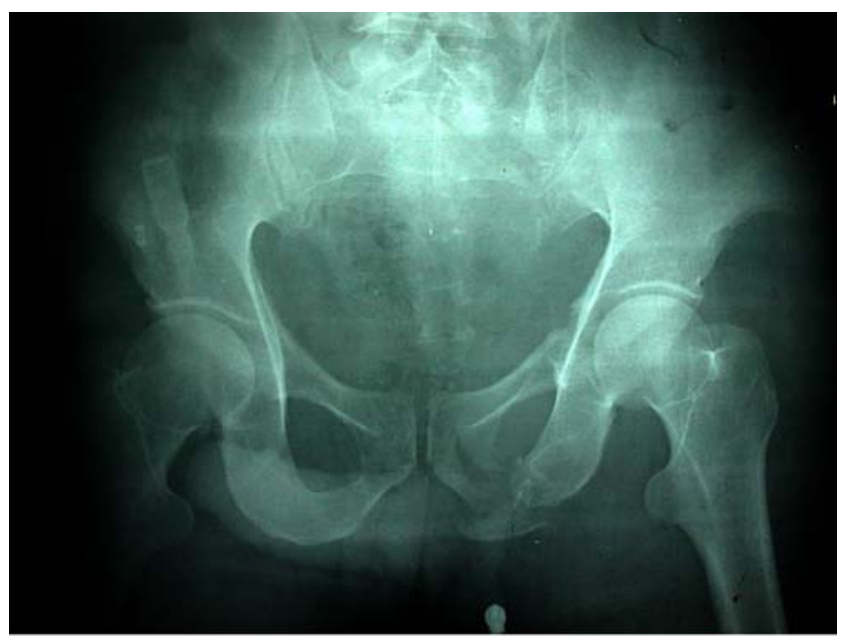

a

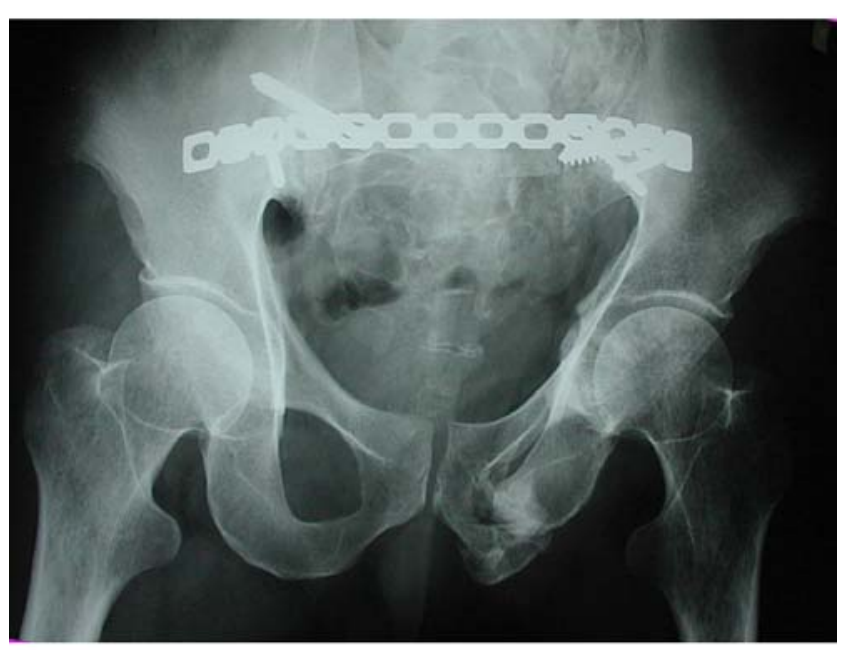

b

Fig. 2 A 34-year-old male had a history of a fall from height. He suffered left-sided type $\mathrm{C}$ transforaminal sacral fracture with injury of the $\mathrm{S} 1+\mathrm{S} 2$ roots and left pubic bone fracture, which represented the vertical limb of the associated non-displaced "T-shaped" acetabular fracture (a). He recovered completely, after 13 months from primary decompression, with good radiological and functional scores (b)
Table 2 Functional and radiological results relationship

\begin{tabular}{lllllll}
\hline \multicolumn{5}{c}{ Functional results } \\
\cline { 2 - 7 } $\begin{array}{l}\text { Radiological } \\
\text { results }\end{array}$ & Excellent & Good & Fair & Poor & Total & $\begin{array}{l}\text { One- } \\
\text { way } \\
\text { ANOVA } \\
\text { test }\end{array}$ \\
\hline Excellent & 4 & 7 & 3 & 2 & 16 cases & $P=$ \\
Good & 5 & 4 & 1 & 1 & 11 cases & $0.434^{*}$ \\
Fair & 0 & 2 & 2 & 0 & 4 cases & \\
Poor & 0 & 0 & 1 & 0 & 1 cases & \\
Total & 9 & 13 & 7 & 3 & 32 cases & \\
\hline
\end{tabular}

*insignificant $P$ value

results (with subjectively non-disturbing residual sensory deficits in one case and motor deficits in four cases and one case respectively), seven cases had fair results with partial motor and sensory recovery but still agonising deficits and three cases had poor results with no recovery. All unsatisfactory results were due mainly to: posterior sacroiliac pain in two cases with persistent positive Patrick's test, motor deficits in six cases and both motor deficits and sexual problems in two cases. Although satisfactory radiological scores were associated with satisfactory functional scores in most cases (Table 2), the relationship was statistically insignificant $(P=0.434)$.

No motor recovery occurred in three cases and all had: L5+S1 root involvement, secondary- and tertiary-phase surgery and, in spite of their bad functional scores, they had excellent and good radiological results, as shown in Tables 2 and 3. Partial motor recovery happened in eight cases and complete recovery in 21 cases. The average radiological and clinical healing time was 10 (range 8-13) weeks and the average time for maximal neurological recovery was 13 (range 8-22) months. The operated cases in the primary phase had significantly $(P=0.008)$ better recovery (Table 3$)$.

The neurological recovery significantly had the worst outcome when it was related to $\mathrm{L} 5+\mathrm{S} 1$ roots injuries, lowest motor power grades, delayed surgical interference, comminuted sacral fractures, vertical shear injuries, older age groups (above 41 years old), pedestrian trauma and in the absence of agonising radicular pain before surgery. Moreover, the recovery was better, but insignificantly so $(P=$ 0.067), when the preoperative posterior displacement was less than $10 \mathrm{~mm}$ (Table 3).

Complications were faced in nine cases. Four cases had early infection and five cases had late urological problems and heterotopic ossification. Superficial infection occurred in three cases and was controlled by extended antibiotic therapy for two weeks. Deep infection with wound disruption complicated one case with Morel-Lavalle lesion, 
Table 3 Factors affecting motor function recovery

\begin{tabular}{|c|c|c|c|c|c|c|}
\hline \multirow[t]{2}{*}{ Factors } & & \multicolumn{5}{|c|}{ Motor function recovery } \\
\hline & & No recovery & Partial recovery & Complete recovery & Total & One-way ANOVA test \\
\hline \multirow[t]{2}{*}{ Gender } & Male & 2 & 4 & 14 & 20 & \multirow[t]{2}{*}{$P=0.067^{*}$} \\
\hline & Female & 1 & 4 & 7 & 12 & \\
\hline \multirow[t]{4}{*}{ Age } & $21-30$ & 1 & 3 & 9 & 13 & \multirow[t]{4}{*}{$P=0.05^{* *}$} \\
\hline & $31-40$ & 0 & 5 & 6 & 11 & \\
\hline & $41-50$ & 1 & 0 & 4 & 5 & \\
\hline & $51-60$ & 1 & 0 & 2 & 3 & \\
\hline \multirow[t]{4}{*}{ Type of trauma } & Pedestrian & 2 & 3 & 4 & 9 & \multirow[t]{4}{*}{$P=0.005^{* *}$} \\
\hline & Motorcycle & 0 & 3 & 4 & 7 & \\
\hline & Car occupant & 0 & 0 & 5 & 5 & \\
\hline & Fall from height & 1 & 2 & 8 & 11 & \\
\hline \multirow[t]{3}{*}{ Mechanism of injury } & $\mathrm{APC}$ & 0 & 5 & 10 & 15 cases & \multirow[t]{3}{*}{$P=0.037 * *$} \\
\hline & VS & 2 & 3 & 5 & 10 cases & \\
\hline & $\mathrm{CM}$ & 1 & 0 & 6 & 7 cases & \\
\hline \multirow[t]{2}{*}{ Initial posterior displacement } & $5-10 \mathrm{~mm}$ & 1 & 2 & 12 & 15 & \multirow[t]{2}{*}{$P=0.067^{*}$} \\
\hline & $11-20 \mathrm{~mm}$ & 2 & 6 & 9 & 17 & \\
\hline \multirow[t]{3}{*}{ Sacral zones } & zone I & 1 & 2 & 7 & 10 cases & \multirow[t]{3}{*}{$P=0.004 * *$} \\
\hline & zone II & 1 & 2 & 9 & 12 cases & \\
\hline & Comminuted & 1 & 4 & 5 & 10 cases & \\
\hline \multirow[t]{4}{*}{ Injured roots } & $\mathrm{L} 5+\mathrm{S} 1$ roots & 3 & 3 & 4 & 10 cases & \multirow[t]{4}{*}{$P=0.024 * *$} \\
\hline & $\mathrm{S} 1+\mathrm{S} 2$ roots & 0 & 3 & 8 & 11 cases & \\
\hline & $\mathrm{S} 1$ root & 0 & 1 & 7 & 8 cases & \\
\hline & $\mathrm{S} 1+\mathrm{S} 2+\mathrm{S} 3$ roots & 0 & 1 & 2 & 3 cases & \\
\hline \multirow[t]{3}{*}{ Motor power grades } & $0-1 / 5$ & 1 & 3 & 3 & 7 cases & \multirow[t]{3}{*}{$P=0.027 * *$} \\
\hline & $2 / 5$ & 1 & 3 & 9 & 13 cases & \\
\hline & $3 / 5$ & 1 & 2 & 9 & 12 cases & \\
\hline \multirow[t]{3}{*}{ Surgery timing } & Primary phase & 0 & 4 & 9 & 13 cases & \multirow[t]{3}{*}{$P=0.008^{* *}$} \\
\hline & Secondary phase & 2 & 1 & 7 & 10 cases & \\
\hline & Tertiary phase & 1 & 3 & 5 & 9 cases & \\
\hline \multirow[t]{5}{*}{ Radicular pain } & None & 2 & 5 & 8 & 15 & \multirow[t]{5}{*}{$P=0.028^{* *}$} \\
\hline & Mild & 1 & 2 & 6 & 9 & \\
\hline & Moderate & 0 & 1 & 5 & 6 & \\
\hline & Severe & 0 & 0 & 2 & 2 & \\
\hline & Total & 3 & 8 & 21 & 32 cases & \\
\hline
\end{tabular}

$\mathrm{APC}=$ anteroposterior compression; $\mathrm{VS}=$ vertical shear; $\mathrm{CM}=$ combined mechanism; $\mathrm{L}=$ lumbar; $\mathrm{S}=$ sacral *insignificant $P$ values

**significant $P$ values

and was managed with parenteral antibiotic, debridement, insertion of vancomycin and tobramycin beads and secondary wound closure after 4 weeks. Urological troubles, urgency and incontinence complicated four cases; three of these cases were males with initially complete rupture of the urethra, all had comminuted sacral fractures with extensive retroperitoneal haematoma, three had $\mathrm{S} 1+\mathrm{S} 2$ roots injury, one had $\mathrm{S} 1+\mathrm{S} 2+\mathrm{S} 3$ roots injury and two had associated partial impotence. Satisfactory recovery from the complications had been noticed at up to 34 months follow up. One case, with initial head injury, had right posterior iliac heterotopic ossification, which was radiologically evident with mild posterior pain on sitting.

\section{Discussion}

In a review of the literature concerning neurological recovery after sacral fractures, Taguchi et al. [20] found that, among the seven cases with neurological deficits, two cases improved completely and five cases improved partially during follow up. Mouhsine et al. [13] had four patients with neurological impairment. They showed a slow but complete recovery after 17 months follow up. Schildhauer et al. [18] had 22 cases with preoperative neurological deficits but only six of them recovered. They explained this low rate by the presence of nerve root avulsions in most of these cases. Bellabarba et al. [1] had ten cases (55\%) with complete improvement of the 
neurological deficits, five cases (28\%) with partial recovery and only three cases (17\%) without recovery. Zelle et al. [24] had 13 patients with a neurological deficit; six patients underwent surgical decompression and seven patients were managed without surgical decompression. Their patients undergoing surgical decompression had significantly better neurological and functional improvement. In this series, 21 cases $(65.6 \%)$ had complete neural recovery, eight cases (25\%) had partial recovery and three cases $(9.4 \%)$ had no recovery. Consequently, these results can stand beside the better findings in the literature and the good recovery could be attributed to early surgical decompression, anatomical reduction, the absence of zone III injuries and no root transection being detected intraoperatively.

The preoperative posterior displacement of more than $1 \mathrm{~cm}$ was associated with less neurological recovery. This could be due to more severe injury to the involved roots or due to more stretching, kinking or compression of the roots by the displaced bony fragments. Likewise, Taguchi et al. [20] reported a significant correlation between the neurological deficits and the initial vertical displacement. Thus, they advised early decompression and anatomical reduction to improve recovery, particularly with vertical displacements more than $1 \mathrm{~cm}$.

The degree of preoperative radicular pain was a significantly good prognostic factor for neurological recovery. The more radicular pain that the patient had, the greater the chance for full recovery after decompression. Similarly, Zelle et al. [24] had three cases with severe radicular pain, all of them recovered completely after decompression. Therefore, we consider the radicular pain to be an indicator for good recovery and as a valuable invitation for early decompression of the incompletely injured roots.

Early decompression and fixation, in the primary phase, was associated with significantly better recovery. This corroborated the findings of Latenser et al. [8], who stated that improved survival rates, outcomes and reduced major complications have been shown for pelvic ring stabilisation procedures performed within $72 \mathrm{~h}$ of injury. Denis et al. [3] suggested the need for decompression within 2 weeks to optimise neural recovery. Furthermore, another study found out that late decompression, especially for L5 root entrapment, did not improve the neurological deficits but could improve chronic radiculopathy [20].

Regardless of our satisfactory radiological scores seven cases, had fair and poor functional scores due to their unrecovered neurological injuries. This supports the argument that permanent neurological injury may aggravate the functional outcome, even if the reduction of the pelvic ring fracture is anatomical [10].

Only three cases $(9.4 \%)$ had immediate postoperative unsatisfactory posterior radiological results due to incomplete reduction but no late redisplacement; therefore, we suggest that the reconstruction plate alone is enough to achieve safe and stable internal fixation without the need for additional iliosacral screws, which have the disadvantages of iatrogenic nerve injuries, malpositioning and less stable fixation, especially with severe comminution $[5,17]$.

Although Matta [12] advised internal fixation of pubic fractures only when the initial displacement is more than $20 \mathrm{~mm}$, according to the radiological results in our series, it is preferable to internally fix the anterior pubic arch fractures in type $\mathrm{C}$ injuries. Also, Lindahl and Hirvensalo [10] documented in their study of $2 / 16$ patients that the position of the initially minimally displaced and unfixed fracture of the pubic rami worsened, even though the posterior injury was adequately fixed.

Unfortunately, the prevention of wound infection in sacral surgery for polytraumatised patients with local soft tissue injury remains an elusive goal. Superficial infection happened in three cases $(9.4 \%)$ and deep infection with wound disruption complicated one case $(3.1 \%)$ with a Morel-Lavalle lesion. Likewise, Shirahama [19] reported an $11.1 \%$ infection rate in two cases with Morel-Lavalle lesion and Schildhauer et al. [18] reported a 5.9\% infection rate in two patients and, despite subsequent debridement and lavage, both required early hardware removal.

Late urogenital troubles affected four cases (12.5\%), all had a comminuted fractured sacrum, and they had partial satisfactory improvement from 11 up to 34 months follow up, with an average 18 months. Although Gunterberg [6] has shown that the unilateral supply of S2 and S3 nerve roots is sufficient for good sphincteric and sexual functions, and Gibbons et al. [4] stated that severe unilateral root injury did not affect sphincter tone in their 44 cases of sacral fractures, urogenital problems in this series were associated with unilateral root injury. This can be explained by one or more of the following factors: the first is fibrosis of the huge expanding retroperitoneal haematoma which was present in all of the four cases; the second is diabetic peripheral neuropathy, which was present in two of the cases studied; and the third is the presence of initial complete urethral rupture in three of them.

Although no ipsilateral sacroiliac joint injury was present, as evidenced by CT scans, two cases $(6.2 \%)$ had persistent sacroiliac pain and positive abduction-external rotation test. This can be explicated, according to Rosenberg et al. [16] by the anatomical fact that the first two sacral nerves (in addition to the superior gluteal and obturator nerves) cross and supply the synovial part of the sacroiliac joint anteriorly, with the pain being felt along the distribution of the irritated nerves.

There were no problems, such as prominent hardware or uncontrolled deep infection, which necessitated the removal of the implants in our early follow up periods, as documented in many studies $[1,13]$. This could be related 
to application of the reconstruction plate deep to the erector spinae and gluteal muscles, and the creation of a deep notch, which can adapt the reconstruction plate width and height without any implant prominence, especially in thin patients and those with posterior soft tissue injury.

Although neurological complications of sacral fractures were associated with poor outcomes in many studies [15, $19,22]$, our results give a good outcome for those injuries, provided that decompression, anatomical reduction and rigid fixation is achieved early, particularly in the primary phase. The reconstruction plate alone is a good and safe tool to achieve rigid posterior fixation, without the need for added, unsafe and less stable iliosacral screws.

Acknowledgement The author is grateful to Professor Ahmed ElElimi and Professor Mohammed Shafeek for their useful suggestions during the study and their great moral and scientific support.

\section{References}

1. Bellabarba C, Schildhauer TA, Vaccaro AR, Chapman JR (2006) Complications associated with surgical stabilization of high-grade sacral fracture dislocations with spino-pelvic instability. Spine 31 (11 Suppl):S80-S88

2. Browner BD, Cole JD, Graham JM, Bondurant FJ, NunchuckBurns SK, Colter HB (1987) Delayed posterior internal fixation of unstable pelvic fractures. J Trauma 27(9):998-1006

3. Denis F, Davis S, Comfort T (1988) Sacral fractures: an important problem. Retrospective analysis of 236 cases. Clin Orthop Relat Res 227:67-81

4. Gibbons KJ, Soloniuk DS, Razack N (1990) Neurological injury and patterns of sacral fractures. J Neurosurg 72(6):889-893

5. Griffin DR, Starr AJ, Reinert CM, Jones AL, Whitlock S (2003) Vertically unstable pelvic fractures fixed with percutaneous iliosacral screws: does posterior injury pattern predict fixation failure? J Orthop Trauma 17(6):399-405

6. Gunterberg B (1976) Effects of major resection of the sacrum. Clinical studies on urogenital and anorectal function and a biomechanical study on pelvic strength. Acta Orthop Scand Suppl 162:1-38

7. Henderson RC (1989) The long-term results of nonoperatively treated major pelvic disruptions. J Orthop Trauma 3(1):41-47
8. Latenser BA, Gentilello LM, Tarver AA, Thalgott JS, Batdorf JW (1991) Improved outcome with early fixation of skeletally unstable pelvic fractures. J Trauma 31(1):28-31

9. Lindahl J, Hirvensalo E, Boöstman O, Santavirta S (1999) Failure of reduction with an external fixator in the management of injuries of the pelvic ring. Long-term evaluation of 110 patients. J Bone Joint Surg Br 81(6):955-962

10. Lindahl J, Hirvensalo E (2005) Outcome of operatively treated type-C injuries of the pelvic ring. Acta Orthop 76(5):667-678

11. Majeed SA (1989) Grading the outcome of pelvic fractures. J Bone Joint Surg Br 71(2):304-306

12. Matta JM (1996) Indications for anterior fixation of pelvic fractures. Clin Orthop Relat Res 329:88-96

13. Mouhsine E, Wettstein M, Schizas C, Borens O, Blanc $\mathrm{CH}$, Leyvraz PF, Theumann N, Garofalo R (2006) Modified triangular posterior osteosynthesis of unstable sacrum fracture. Eur Spine J 15(6):857-863

14. Oestern HJ, Tscherne H, Sturm J, Nerlich M (1985) Classification of the severity of injury. Unfallchirurg 88(11):465-472

15. Pohlemann T, Bosch U, Gänsslen A, Tscherne H (1994) The Hannover experience in management of pelvic fractures. Clin Orthop Relat Res 305:69-80

16. Rosenberg D, Baskies AM, Deckers PJ, Leiter BE, Ordia JI, Yablon IG (1984) Pyogenic sacroiliitis. An absolute indication for computerized tomographic scanning. Clin Orthop Relat Res 184:128-132

17. Routt ML Jr, Simonian PT, Mills WJ (1997) Iliosacral screw fixation: early complications of the percutaneous technique. J Orthop Trauma 11(8):584-589

18. Schildhauer TA, Josten Ch, Muhr G (2006) Triangular osteosynthesis of vertically unstable sacrum fractures: a new concept allowing early weight-bearing. J Orthop Trauma 20(1 Suppl):S44-S51

19. Shirahama M (2005) Surgical treatment of vertically unstable sacral fractures using a new plate. Kurume Med J 52(1-2):9-18

20. Taguchi T, Kawai S, Kaneko K, Yugue D (1999) Operative management of displaced fractures of the sacrum. J Orthop Sci 4 (5):347-352

21. Tile M (1988) Pelvic ring fractures: should they be fixed? J Bone Joint Surg Br 70(1):1-12

22. Tornetta P 3rd, Matta JM (1996) Outcome of operatively treated unstable posterior pelvic ring disruptions. Clin Orthop Relat Res 329:186-193

23. Tscherne H, Regel G, Pape HC, Pohlemann T, Trettek C (1998) Internal fixation of multiple fractures in patients with polytrauma. Clin Orthop Relat Res 347:62-78

24. Zelle BA, Gruen GS, Hunt T, Speth SR (2004) Sacral fractures with neurological injury: is early decompression beneficial? Int Orthop 28(4):244-251 